\title{
Dos campos de futebol para os campos de batalha: uma análise da Guerra dos Bálcãs
}

\author{
From the football pitches to battlefields: \\ an analysis of the Balkan War
}

\author{
Makchwell Coimbra Narcizo \\ Universidade Federal de Goiás (UFG), Goiânia / Brasil \\ Doutorando em História Social, Universidade Federal de Uberlândia (UFU) \\ makch01@hotmail.com
}

\begin{abstract}
RESUMO: A Guerra dos Balcãs ganhou importância na história recente da Europa por conta de sua violência e crueldade, algo que os europeus julgavam superado no continente, visto que ocorreu no fim do século XX. Apesar de ser algo quase que folclórico o fato de que os conflitos tenham começado em uma partida de futebol, a importância desse esporte no desenrolar da guerra é pouco explorada. A intenção do presente trabalho é tratar da influência do futebol não apenas no início, mas no desenrolar dos conflitos, passando por uma necessária reflexão sobre identidade.
\end{abstract}

Palavras-chave: Guerra dos Balcãs; Futebol; Identidade.

ABSTRACT: the Balkan War gained in importance in the recent history of Europe because of its violence and cruelty, which Europeans thought that had been overcome in the continent, since it happened in the end of the 20th century. Even though the conflicts started in a football match, the importance of this sport as the war unfolded is very little studied. The purpose of the present work is to deal with the influence of football not only in the beginning, but in the progress of the conflicts, and including a needed reflection about identity.

KEYWORDS: Balkan War; Football; Identity. 


\section{CONSIDERAÇõES INICIAIS}

Os Bálcãs tornaram-se um local bastante conflituoso com a dissolução da URSS, precisava-se apenas de um estopim para deflagrar uma guerra, isso ocorrera em 13 de maio de 1990, em uma partida de futebol realizada em Zagreb entre o Estrela Vermelha (Belgrado) e o Dínamo (Zagreb). ${ }^{1} 0$ futebol entra de forma destacada na guerra, não meramente por acaso, pois tanto Slobodan Milošević quanto Franjo Tuđman, líderes sérvio e croata respectivamente, eram homens ligados ao futebol, mais tarde a torcida organizada do Estrela Vermelha se tornaria a tropa de choque de Milošević, sendo os mais ativos agentes de limpeza étnica, genocidas altamente eficientes.

0 que ocorrera nos Bálcãs é uma das mais emblemáticas páginas da história do futebol. É rara e ao mesmo tempo paradoxal a participação de uma torcida em uma ação bélica e de "limpeza étnica", é preferível que o futebol seja lembrado pelas belas batalhas dentro dos limites do esporte, mas não nos enganemos, o futebol faz parte de um mecanismo maior, hora ou outra alguém se atenta para isso e usa a paixão do torcedor em benefício próprio.

Norbert Elias e Eric Dunning² apontam que as investigações tradicionais sobre o desporto erram em trata-lo como algo que deve sanar os problemas da sociedade, como um fator contributivo com a sociedade. Partindo de uma análise oriunda da Sociologia Figuracional, os autores defendem o estudo das relações humanas de forma processual, assim, o futebol se apresenta como fundamental para se entender a sociedade. 0 futebol não é algo alheio a sociedade, ele se desenvolve com ela.

\footnotetext{
${ }^{1}$ Ao contrário do que se possa imaginar eram duas equipes de altíssimo nível, sendo que o Estrela Vermelha sagrar-se-ia campeão da Taça dos Campeões da Europa, que mais tarde mudaria de nome para Uefa Champions League (mais importante torneio de clubes da Europa) um ano depois, além de conquistar o Mundial Interclubes na seqüência, contando com jogadores de altíssimo gabarito, tais como: Vladimir Jugović, llija Najdoski, Miodrag Beleodici, Dejan Savićević, Darko Pančev, Siniša Mihajlović e Robert Prosinečki, do lado do Estrela Vermelha, o Dínamo contava com Tomislav Butina no gol e com Zvonimir Boban no meio. Jogadores que sem dúvidas foram protagonistas no mundo do futebol nas décadas de $1980 \mathrm{e}$ 1990, sendo base para as seleções da lugoslávia e Croácia na Copa do Mundo de 1998, a qual tiveram excelentes participações. O Estrela Vermelha contava com jogadores de várias parte da lugoslávia, dentre os quis alguns croatas, como o caso de Robert Prosinečki.

${ }^{2}$ ELIAS; DUNNING. A busca da excitação, p. 39.
} 
Busca-se aqui uma tentativa de trazer de volta para a discussão o problema dos Bálcãs, que há menos de 15 anos chocava o mundo com suas imagens de terror, e que hoje, poucos sabem onde fica ou muito menos o que ocorre por lá. Essa região que hoje é ignorada pelos noticiários continua com problemas reais, mas com pouco apelo midiático, visto que, tragédias cotidianas não importam mais, o que vende hoje são as tragédias palestinas, da Síria ou de atentados em solo europeu ou estadunidense. Os Bálcãs não são meramente um terreno montanhoso entre a Ásia e a Europa, é um local com uma história rica e fascinante.

Uma análise da Guerra dos Bálcãs deve levar em consideração a construção e reconstrução de identidades, visto que, existem os bósnios, mas também os bosníacos, que são bósnios, mas são mulçumanos, pois existem os bósnios de ascendência sérvia, mas também os de ascendência croata, na verdade é Bósnia-Herzegovina. Tem também os eslovenos, que são eslavos e germânicos homogeneizados, mas que já foram todos iugoslavos.

A Croácia é um Estado de croatas, com exceção dos croatas da BósniaHerzegovina, que preferiram ser bósnios. Tem a Sérvia e Montenegro, na verdade Sérvia é um e Montenegro outro, hoje é apenas Sérvia, na Sérvia, vivem os sérvios, aliás, existem sérvios por toda região dos Bálcãs, na verdade são sérvios do Norte, do Sul, do Leste, mas são sérvios, todavia tem os sérvios da Eslovênia, mas também não podemos nos esquecer dos sérvios do Kosovo, que se dizem mais sérvios, mas vivem no Kosovo. Os montenegrinos estão em Montenegro, que desde 2006 é independente politicamente.

Tem também a Macedônia, que nunca teve uma etnia que reivindicasse um território, mas já que o general Josip Broz Tito criou a Macedônia, os búlgaros, romenos, egípcios, sérvios, albaneses que por ali estavam, tornaram-se macedônios.

Existe também a Albânia, formada por albaneses, que já quiseram a independência do Kosovo, mas também têm a Romênia e a Bulgária, que tem em sua maioria romenos e búlgaros respectivamente.

Sim, é essa diversidade de identidades e de nacionalidades que constitui os Bálcãs, muitas vezes é mais fácil saber quem não se é do que quem se é. Portanto, se quisermos falar de criação de identidades, os Bálcãs e seus conflitos recentes são excelentes objetos de pesquisa. 
A intenção no presente trabalho não é fazer análise do futebol sérvio em sua essência, mas sim, analisar a Guerra dos Bálcãs, suas motivações e desdobramentos, tendo o futebol como ponto de partida. Na busca de compreender a ação de determinados grupos, os quais protagonizaram o crime organizado na região dos Bálcãs buscaremos mostrar como o futebol foi usado como um objeto de construção de identidades para atender determinações políticas.

\section{QUESTÃO DE IDENTIDADE}

Abordar questões sobre identidade em Ciências Humanas e Sociais é tão necessário quanto complexo, visto que identidade é um conceito polissêmico de dimensões multifacetadas e até mesmo contraditórias. Isso se dá em certa medida porque identidade é ligada ao reconhecimento, suscitando teorias e explicações que buscam combinar a relação entre sujeito e significados coletivos. Desta feita, identidade pode ser considerada uma categoria de análise, ou seja, um recurso teórico que que auxilia na compreensão de um fenômeno.

O contexto social oferece condições para que a identidade seja construída e reconstruída, visto que ela nunca é fixa. O conceito "identidade" pode ser utilizado para expressar a construção singular que o sujeito faz de si, construída na relação com as outras pessoas, mas nunca fechada em si ou finalizada. Ela não é construída, mas vai sendo construída ao longo da vida, por isso, mudando.

Assim, sabendo da gama de possibilidades e de abordagens teóricas, visase aqui, tratar uma perspectiva de identidade que não é absoluta e nem única, mas que serve como categoria de análise para interpretar o objeto em questão. Ao falarmos de construção de identidades nos apoiamos inicialmente em Kathriyn Woodward, para tal consideração vejamos:

São quatro horas da manhã. Estou no posto de comando da milícia sérvia local, em uma casa de fazenda abandonada, a 250 metros da linha de frente croata... Não na Bósnia, mas nas zonas de guerra da Croácia central. 0 mundo não está mais olhando, mas todas as noites as milícias croatas e sérvias trocam tiros e, às vezes, pesados ataques de bazuca.

Esta é guerra de cidade pequena. Todo mundo conhece todo mundo: eles foram, todos, à escola juntos; antes da guerra alguns deles trabalhavam na mesma oficina; namoravam as mesmas garotas. Toda noite, eles se comunicam 
na rádio "faixa do cidadão" e trocam insultos - tratando-se pelos respectivos nomes. Depois saem dali para tentar se matar uns aos outros.

Estou falando com soldados sérvios - reservistas cansados, de meia idade, que preferiam estar em casa, na cama. Estou tentando compreender por que vizinhos começam a se matar uns aos outros. Digo, primeiramente, que não consigo distinguir sérvios de croatas. "O que faz vocês pensarem que são diferentes?"

O homem com quem estou falando, pega um maço de cigarros do bolso de sua jaqueta cáqui. "Vê isso? São cigarros sérvios. Do outro lado, eles fumam cigarros croatas."

"Mas eles são, ambos, cigarros, certo?"

"Vocês estrangeiros não entendem nada" - ele dá de ombros e começa a limpar a metralhadora Zastovo.

Mas a pergunta que eu fiz incomoda-o, de forma que alguns minutos mais tarde, ele joga a arma no banco ao lado e diz: "Olha, a coisa é assim. Aqueles croatas pensam que são melhores que nós. Eles pensam que são europeus finos e tudo mais. Vou lhe dizer uma coisa. Somos todos lixo dos Bálcãs. ${ }^{3}$

Antes de fazermos as necessárias considerações acerca das construções de identidade expressas na passagem supracitada, usamos a frase do miliciano sérvio acerca dos cigarros sérvio e croata para apresentarmos um personagem fundamental da Guerra dos Bálcãs e de nossa análise, trata-se de Željko Ražnatović, mais conhecido como Arkan, ${ }^{4}$ por que apresentá-lo agora? É porque o cigarro que sérvios, croatas e o restante dos Bálcãs fumavam, era fornecido no período por Željko Ražnatović, aliás, o tráfico deles fora o principal ramo de atividade de Arkan no pós Guerra dos Bálcãs, como nos aponta Misha Glenny, ${ }^{5}$ portanto, não era cigarro sérvio nem croata, na verdade se tratava do mesmo cigarro. Voltaremos a falar de Arkan em momento mais propício.

No trecho que nos é apresentado por Ignatieff, notamos que o relato é bem mais que uma mera exposição sobre a guerra, é um relato sobre identidades. Identidades que são apresentadas como totalmente diferentes, aliás, há um esforço do miliciano sérvio para destacar tal diferença. Nesse caso, uma identidade só existe em função da outra, a respeito Kathryn Woodward diz o seguinte:

Essa história mostra que a identidade é relacional. A identidade sérvia depende, para existir de algo fora dela: a saber, de outra identidade (Croácia), de uma identidade que ela não é, que difere da identidade sérvia, mas que, entretanto fornece as condições para que ela exista. A identidade sérvia se distingue por aquilo que ela não é. Ser um sérvio é ser um "não croata". A identidade é, assim, marcada pela diferença. ${ }^{6}$

\footnotetext{
${ }^{3}$ IGNATIEFF apud WOODWARD. Identidade e diferença, p. 7-8.

${ }^{4}$ Arkan é um dos três nomes que são lembrados ao se falar da violência e das atrocidades da Guerra dos Bálcãs, os outros dois são o croata Ante Gotovina, e sérvio Ratko Mladić.

${ }^{5}$ GLENNY. McMáfia, p. 56-58.

${ }^{6}$ WOODWARD. Identidade e diferença, p. 9.
} 
A (re)construção das identidades nos Bálcãs é feita levando em consideração a exclusão de uma identidade que outrora sustentara o Estado Iugoslavo, o que está em jogo é principalmente a diferença, as semelhanças devem ser anuladas, se antes o "não ser europeu" os uniam, agora não serve como algo aglutinador.

Com o desmantelamento da URSS, o fim da Iugoslávia era questão de tempo, nesse momento começou uma corrida para a (re)construção das identidades nacionais, levando em consideração grupos étnicos, sobre isso Woodward salienta:

Em outras palavras, a afirmação da identidade nacional é historicamente específica. Embora se possa remontar as raízes das identidades nacionais em jogo na antiga Iugoslávia à história das comunidades que existiam no interior daquele território, o conflito entre elas surge em um momento particular. Nesse sentido, a emergência dessas diferentes identidades é histórica; ela está localizada em um ponto específico no tempo. Uma das formas pelas quais as identidades estabelecem sua reivindicação é por meio do apelo a antecedentes históricos. Os sérvios, os bósnios e os croatas tentam reafirmar suas identidades, supostamente perdidas, buscando-as no passado, embora, ao fazêlo, eles possam estar realmente produzindo novas identidades. ${ }^{7}$

Para a construção da identidade nacional, vários artifícios são escalados, um deles é dar uma significação ao passado, dar significação segundo as aspirações do presente. A construção dessa identidade faz uso de aspectos simbólicos constantemente, não nos esqueçamos que o uso do simbólico faz parte da busca do domínio do "real" como nos indica Roger Chartier. ${ }^{8}$

Woodward apresenta a formação indentitária pela diferença, ${ }^{9}$ ou seja, por aquilo que você não é, uma representação que é construída simbólica e socialmente. Existe uma representação que abarca praticas de significações e sistemas simbólicos, nos quais os significados são produzidos, orientando assim os sujeitos.

Slobodan Milošević na tentativa de manter a Grande Iugoslávia sob o domínio sérvio tratou de fazer uso do nacionalismo sérvio, afinal compreendia que se não soubesse manipular tal nacionalismo, esse poderia se virar contra seu governo, o que aconteceria mais tarde. A identidade sérvia passa a ser construída a partir dos outros, o primeiro outro é o croata, depois o outro se estende para o

\footnotetext{
${ }^{7}$ WOODWARD. Identidade e diferença, p. 11.

${ }^{8}$ CHARTIER. A construção estética da realidade, p. 34.

${ }^{9}$ WOODWARD. Identidade e diferença, p. 17.
} 
bósnio, esloveno, macedônio em uma reconstrução constante o sérvio depende de sua relação com o outro, como trata Woodward.

\section{FUTEBOL, POLÍTICA E GUERRA}

Milošević assim como Nicolau Sevcenko10 sabia que as batalhas simbólicas que ocorrem dentro de um estádio de futebol podem ganhar proporções fora deles, sendo assim, Milošević resolveu fazer com que a torcida do FK Estrela Vermelha de Belgrado jogasse a seu favor.

Uma pergunta logo se torna necessária: Por que o FK Estrela Vermelha de Belgrado e não o FK Partizan Belgrado, o outro grande time da Sérvia? Dois motivos são fundamentais para tal escolha: 0 primeiro diz respeito ao surgimento dos dois times. Enquanto o Estrela Vermelha foi fundado e patrocinado pela polícia iugoslava, o Partizan era o time oficial do exército na Iugoslávia, ${ }^{11}$ sendo o time favorito do marechal Tito que reprimia toda ação de nacionalismo sérvio; o outro motivo fundamental é que os torcedores do Estrela Vermelha vinham tendo atitudes em favor de um nacionalismo sérvio já na década de 1980, com cânticos como "Sérvia sim, Iugoslávia não".12

0 primeiro-ministro iugoslavo que devia grande parte de sua popularidade fazendo uso do nacionalismo sérvio sabia que esse deveria ser usado, mas dentro de seu controle. Ele fora diretor do Estrela Vermelha antes de se tornar primeiro-ministro da Iugoslávia, sabia da força de sua torcida, sabia também que havia certa falta de comando nessa torcida que começava a destacar-se como uma das mais violentas da Europa.

Milošević colocou um homem de confiança seu, e fanático pelo Estrela Vermelha, para organizar a torcida, trata-se de Željko Ražnatović, o Arkan, que desde meados da década de 1980 servia como "capanga" de Milošević, fazendo carreira paralela como gangster. Antes de retornar para a Iugoslávia Arkan passara

\footnotetext{
${ }^{10}$ SEVCENKO. Futebol, metrópoles e desatinos, p. 30-37.

${ }^{11}$ O nome Partizan refere-se ao Exército Popular da Libertação da lugoslávia, que lutou na Segunda Guerra Mundial contra as forças do Eixo nos Bálcãs, os Partizans eram os soldados que lutaram contra a dominação nazista nos Bálcãs.

${ }_{12}$ FOER. Como o futebol explica o mundo, p. 23.
} 
a vida cometendo delitos, sendo condenado por eles e escapando ileso por vários países da Europa, o que já lhe rendia uma fama considerável mesmo antes de comandar seus "Tigres".

Arkan reestruturou a Torcida Organizada do Estrela Vermelha, trocando o nome de "Ciganos" (um insulto dos adversários que havia sido adotado, tal como acontece com diversas torcidas) para Delije's, que significa heróis em um dialeto local. Arkan adotou uma disciplina militar na torcida, fez com que os torcedores cortassem os cabelos, se barbeassem e não bebessem em dia de jogos. Assim, ganhou o respeito de todos, tanto de dirigentes quanto dos torcedores. ${ }^{13}$

Ao mesmo tempo em que o nacionalismo sérvio estava controlado e jogando a favor de Milošević, outros nacionalismos na Iugoslávia foram alimentados, tal como o esloveno, bósnio e croata, a situação estava incontrolável.

Franjo Tuđman tornara-se presidente do NK Dínamo Zagreb e fazia do time um baluarte do nacionalismo croata, em jogos do Dínamo exibiam cantos de ofensa aos sérvios, muitos deles relembrando episódios de quando os nazistas com o apoio croata reprimiram os sérvios.

Segundo José Augusto Lindgren Alves, ${ }^{14}$ a situação mudou durante a década de 1990, visto que na década anterior pouquíssimas pessoas na Iugoslávia queriam o desmembramento do Estado, mas as atitudes centralizadoras de Milošević causaram insatisfação em outros líderes nacionalistas, especialmente croatas e eslovenos. Ainda segundo Lindgren Alves, haviam proposto uma confederação, veementemente recusada por Milošević que alegara a superioridade dos sérvios.

O que os líderes ultranacionalistas da Iugoslávia fizeram, não constitui em nenhuma inovação, apenas aproveitaram-se de algum tipo de estímulo, interno e externo, para fomentar uma exaltação nacionalista que antes não impedia o convívio. Fazendo uso do que qualquer líder ultranacionalista faz, usar de seu carisma e manipular as pessoas usando suas frustrações pessoais, usando uma fórmula simples e de sucesso: "nós somos melhores, mas historicamente prejudicados e, a culpa é sempre do vizinho".

\footnotetext{
${ }^{13}$ FOER, Franklin. Como o futebol explica o mundo, p. 24-25.

${ }^{14}$ ALVES. Os Bálcãs novamente esquecidos, p. 55-83.
} 
Jean-Yves Camus e René Monzart mostram que no período abordado é um período de crescimento em solo europeu em que existe a consolidação de um nacionalista de cunho xenófobo, que se fortalece especialmente no fim da década de 1980.15

Estava armado o contexto para o grande clássico da Iugoslávia, ${ }^{16}$ o jogo realizado no Estádio Makisimir em Zagreb (Croácia) deflagrou a Guerra pela Independência Croata. Antes do jogo, sérvios e croatas já se enfrentavam pelas ruas de Zagreb, dentro do estádio as ofensas se multiplicavam, de um lado os Delije's cantavam "vamos matar Tuđman", do outro os Bad Boys Blues (torcida organizada do Dínamo Zagreb) respondiam com saudações nazistas. Antes do final do primeiro tempo, começou uma briga generalizada entre sérvios e croatas, a polícia (sérvia) começou a reprimir violentamente os croatas, o que gerou ainda mais ira nos croatas que dominaram os policiais e foram pra cima dos sérvios. A confusão continuou fora do estádio, estendendo-se por toda Zagreb e depois por toda a Iugoslávia central, estava iniciada a guerra. ${ }^{17}$

Duas imagens se destacam em tal episódio, uma do jogador Zvonimir Boban, habilidosíssimo meio campo croata que então defendia o Dínamo Zagreb atacando um policial sérvio (que mais tarde se descobriu que era esloveno) com uma "voadora" no pescoço; a outra é de Arkan que fazia a proteção do treinador do Estrela Vermelha. ${ }^{18}$

Não pensem que a participação dos Delije’s na Guerra dos Bálcãs termina por aqui, agora que vem a parte mais impressionante. Milošević teve problemas com um exército oficial desde o início dos conflitos, afinal, tal exército tinha sido formado pelos comunistas para preservar a unidade do Estado Iugoslavo, além do

\footnotetext{
${ }^{15}$ CAMUS; MONZAT. Les droites nationales et radicales en France, p. 104-105.

${ }^{16}$ Antes do desmembramento da lugoslávia Dínamo Zagreb x Estrela Vermelha era o maior clássico do país, especialmente porque um era o melhor time croata e o outro um dos melhores times sérvios, já que as noções de nacionalismo passavam longe do Partizan, hoje é Partizan $\mathrm{x}$ Estrela Vermelha o maior clássico da Sérvia e da Croácia é Dínamo Zagreb x Hayduk Split. Os quatro times referidos dominaram o campeonato lugoslavo desde a formação da Grande lugoslávia, com exceção das temporadas $65 / 66$ que o título ficou com o Voyvodina Novi Sad, 66/67 tendo como campeão o FK Sarayevo e 88/89 quando novamente o Voyvodina Novi Sad fora o campeão, todos os títulos ficaram entre os quatro times supra citados. Conf. www.fifa.com.

${ }^{17}$ FOER. Como o futebol explica o mundo, p. 22-24.

${ }^{18}$ As imagens podem ser vistas gratuitamente no sítio Youtube.
} 
mais, para as pretensões de Milošević um exército extraoficial era bem mais eficiente. Deu plenos poderes para Arkan criar sua própria milícia armada. ${ }^{19}$

Arkan recrutou seus soldados no Estádio Marakanã, mais especificamente na ala norte, a ala dos Delidj's, ${ }^{20}$ formando a milícia armada dos Tigrov, ou Tigres de Arkan. Nos treinamentos entoavam as músicas que costumavam cantar nos estádios, documentando cada passo. ${ }^{21}$ Reportagens sobre a ação dos homens de Arkan povoavam as revistas esportivas como a France Footbal e a For-For-Two, sobre tal ação um repórter esportivo sérvio relata:

\begin{abstract}
Eu rebobino os filmes das minhas memórias e distribuo esses bravos rapazes por todos os estádios da Europa. Sei exatamente onde estava cada um deles, quem começou a cantar, quem desfraldou a bandeira, quem acendeu a primeira tocha. 0 Delije deixou os acessórios de seus patrocinadores em algum lugar sobre a abóboda do estádio Marakana e saiu para guerra de rifle na mão. ${ }^{22}$
\end{abstract}

É comum a defesa da tese de que as torcidas organizadas são treinadas sob um cunho militarista e até fascista, como defende Carlos Alberto Pimenta, ${ }^{23}$ ou que o futebol é cercado por uma estética de violência como defende Salomé Marivoet, ${ }^{24}$ ou como Eric Dunning e Norbert Elias que apontam que o próprio "jogo" contém elementos que podem servir como vetor de agressividades. Enquanto a tudo isso, não há dúvidas, sabemos que o futebol mexe com as paixões de seus amantes, mas os Tigres de Arkan levaram isso ao extremo, de torcedores tornaram-se criminosos de guerra.

\footnotetext{
${ }^{19}$ FOER. Como o futebol explica o mundo, p. 24-25.

20 Franklin Foer (2005), comete um equívoco e intitula a Torcida Organizada do Estrela Vermelha de Ultra Bad Boys, fazendo uso do termo Delije's para se referir ao grupo armado liderado por Arkan. Ultra Bad Boys é uma ala da torcida organizada do Estrela vermelha, a Delije's, torcica que ao ser transformada em milícia armada ganha o nome de Tigres. A lógica da torcida organizada do Estrela Vermelha é a mesma das Torcidas Organizadas inglesas e brasileiras, existe a Torcida e os seus "comandos", no caso dos Delije's o principal comando é o dos Ultra Bad Boys, existindo outros comandos tais como: Red Devils, Zulus Warrios, Ultras, Ultra Boys, Brigate, Heroes, KCZ, HCz Padina Corps, Fontana, Belgrado Boys. No Brasil citemos duas Torcidas Organizadas para melhor exemplificar, a Gaviões da Fiel tem como primeiro "comando" o Comando de Itaquera, nem por isso é chamada de "Torcida Itaquera", ou como no caso da Esquadrão Vilanovense, que tem como primeiro "comando" a Primeira Legião, nem por isso é chamada de "Torcida Primeira Legião". É compreensível a confusão de Foer, por não estar inserido em um ambiente de Torcidas Organizadas de times futebol. Ainda seguindo a mesma lógica brasileira os Delije's mantem "alianças" com torcidas de outros clubes, com a Gate 7 do Olympiakos da Grécia e a Torcedores Vermelhos do CSKA Sófia da Bulgária.

${ }^{21}$ Existem várias horas dos treinamentos dos Tigres de Arkan na internet, inclusive no sítio Youtube.

${ }^{22}$ FOER. Como o futebol explica o mundo, p. 25-26.

${ }^{23}$ PIMENTA. Torcidas organizadas de futebol, p. 39-55.

${ }^{24}$ MARIVOET. Violência nos espetáculos de futebol, p. 137-153.
} 
Maurício Murad,25 em uma perspectiva de análise ampla da violência e futebol, discorda que o que o envolve é uma "guerra simbólica" ou uma "violência simbólica". Para tal, defende que o futebol não é meramente uma modalidade esportiva, mas um conjunto de retratos da vida, de metáforas humanas.

Enfim, na concepção de Murad, a violência é um fenômeno universal e histórico, sendo impulsionada por questões inerentes à história estando presente em diversos espaços e temporalidades, o futebol não escapa a ela. Em síntese, o futebol tem violência, ele não é violência. Desta feita, a ação dos ultras do Estrela Vermelha não leva violência dos palcos esportivos para a sociedade, mas é resultante de seu momento histórico violento.

Foram fotos das ações dos Tigres que fizeram com que o Ocidente se virasse contra as atrocidades cometidas nos Bálcãs, fotos de Arkan cumprimentando o presidente da República Sérvia da Bósnia em meio a corpos e outras de seus soldados chutando corpos sem vida, revoltaram o Ocidente $^{26}$. Dentre as imagens mais marcantes dos conflitos dos Bálcãs que chocaram o Ocidente estão algumas feitas pelo fotógrafo estadunidense Ron Haviviv que envolvem os Tigres de Arkan, como destaca reportagem do Le Monde ${ }^{27}$.

Após essas imagens e o seu trabalho ter sido "bem feito", expurgando os croatas dos territórios em que haviam sido enviados, Arkan e seus Tigres retiramse da Guerra, os Tigres voltam a ser Delije's, voltam para casa como criminosos de guerra e heróis de guerra mesmo que possa parecer meio paradoxal, mas também ostentando o título de campeões da Europa e campeões mundiais de futebol, já que participaram da primeira ofensiva sérvia contra os croatas em 1991-1992, e em 1991 o Estrela Vermelha sagrara-se campeão da UEFA Champions League e do Mundial Inter-Clubes, voltaram a ser torcedores. Já Arkan, volta como herói de guerra, sendo figura fácil em programas de TV e em outdoors pelas cidades de maioria sérvia. Nesse período casa-se com Svetlana Cecca uma pop star sérvia, seu casamento foi transmitido para toda Iugoslávia, sim, Arkan é cultuado como herói.

\footnotetext{
${ }^{25}$ MURAD. A violência e o futebol, p. 18-20.

${ }^{26}$ FOER. Como o futebol explica o mundo, p. 26.

${ }^{27}$ LE MONDE. Guerre de Bosnie: Ron Haviviv recontre son image emblématique.
} 
Em 1995 quando tropas croatas começam a retomar os territórios perdidos Arkan reúne novamente seus Tigres e volta à guerra, ações essas que são mais violentas que antes, especialmente na província bósnia de Sasina. ${ }^{28} \mathrm{Se}$ Slobodan Milošević é o "carniceiro dos Bálcãs", Arkan é no mínimo um corvo, ou o príncipe da guerra como descrito pelo The Guardian, ${ }^{29}$ o mesmo jornal salienta que Arkan fora um dos mais procurados criminoso da Europa no período, especialmente por conta de crimes de guerra.

Com o fim da guerra, Arkan estava rico e poderoso demais para viver à sombra de Milošević, continuou sua bem sucedida carreira de gangster, segundo Misha Glenny, ${ }^{30}$ era Arkan o maior mafioso dos Bálcãs no final da década de 1990.

Arkan tentou comprar o FK Estrela Vermelha, que obviamente não fora vendido, Arkan então criou seu próprio time, o FK Obilić em homenagem a um herói do Kosovo que lutara uma batalha em 1389, batalha que fora perdida pelos sérvios (encarnando aqui o caráter de eternas vítimas da história), mas Obilić conseguira matar heroicamente o sultão turco. ${ }^{31}$ Como vimos no início do presente trabalho, a busca de uma resignificação do passado é essencial para se criar novas identidades, Arkan propunha-se ser o novo Obilić.

O FK Obilić conseguiu êxito rapidamente, de um time amador tornara-se campeão Sérvio na temporada 1997/98, o que é bem difícil em um país que o futebol é dominado por dois gigantes locais, aliás, com exceção do FK Partizan Belgrado e o FK Estrela Vermelha, o FK Obilić é o único campeão Sérvio. Relatos dizem que o Obilić só conseguia sucesso com ameaças a jogadores adversários e a árbitros. A UEFA nunca permitiu que o FK Obilić jogasse as competições internacionais.

Arkan e suas atividades no pós Guerra dos Bálcãs agregou inimigos na mesma proporção que agregara seguidores, entre eles a família do próprio Slobodan Milošević, segundo Misha Glenny,32 Arkan foi quem escoltou Zoran Đinđić para Montenegro, o qual mais tarde fora eleito democraticamente primeiro ministro da Sérvia, assumindo o posto de Milošević nas urnas, além de ser

\footnotetext{
${ }^{28}$ STEWART. Hunting the tiger, p.137.

29 THE GUARDIAN. Obtuaries.

${ }^{30}$ GLENNY. McMáfia, p. 59-61.

${ }^{31}$ FOER. Como o futebol explica o mundo, p. 28.

${ }^{32}$ GLENNY. McMáfia, p. 59.
} 
concorrente de Marko Milošević filho de Slobodan em atividades no mercado negro. Arkan fora assassinado em janeiro de 2000.

O FK Obilić continua em atividade, tendo a viúva Cecca Ražnatović (que é como gosta de ser chamada após a morte de Arkan) como presidente, mas sem o mesmo brilho de outrora. Cecca, aliás, ainda cultua a figura de Arkan como um herói.

Com a morte de Arkan encerra-se a participação da torcida dos Delije's na recente vida política dos Bálcãs? Não, o temor de Slobodan Milošević de uma década atrás veio à tona, o nacionalismo que outrora constituiu o apoio dos Delije's a Milošević, agora os colocam como inimigos, afinal "Milošević usou a Sérvia para atender a interesses pessoais". A União dos Estudantes Sérvios e os Delije's encabeçaram os protestos que derrubaram Slobodam Milošević. Torcedores do FK Estrela Vermelha dizem que ocorrera a "Revolução do Estrela Vermelha". ${ }^{33}$ Não é para tanto, mas nas imagens da tomada do Parlamento Sérvio, na ocasião da deposição de Milošević é notório o número de camisas do Estrela Vermelha, podem até não ter promovido a "revolução", mas foram agentes importantes em sua constituição.

\section{CONSIDERAÇõES FINAIS}

A perspectiva de análise apresentada aqui é diferente da perspectiva de Maurício Murad, que trata a violência no futebol pensando como ela é transportada da sociedade para o esporte, que é parte dela, aqui, a violência parte do estádio para a sociedade de um modo geral. Contudo, a conclusão é a mesma, pois os eventos ocorridos com participação da torcida do Estrela Vermelha não são por causa do futebol, visto que o futebol não carrega consigo uma violência própria, mas essencialmente por causa da sociedade - sua temporalidade, sua realidade histórica, sua violência.

Um componente essencial para o deflagrar e o desenrolar da guerra é a forma como as identidades são construídas e reconstruídas. No caso abordado foram utilizadas como capital político, o qual foi levado ao extremo, proporcionando a guerra mais sangrenta em território europeu nos últimos anos.

${ }^{33}$ FOER. Como o futebol explica o mundo, p. 28. 
Essas identidades, constituídas a partir da diferença, tão marcante nos Balcãs, foram constituídas a partir da construção social do outro, do diferente.

A guerra, mas também as identidades reconfiguraram a antiga Iugoslávia, reconfigurou também o ódio, ambos refletiram no futebol, que em contrapartida participou ativamente da própria guerra que reconfigura politicamente, geograficamente, culturalmente e especialmente, traz um marco importante na memória da região e a forma como ela é gerida. Que por sua parte, participa da construção de novas identidades.

O futebol de hoje na região dos Balcãs não é o mesmo, mas não o é porque a região também não é a mesma, se reconstruiu a partir da construção de novas identidades, que não estão prontas e se reconstroem o tempo todo. 0 futebol está envolto nisso, ele participa das mudanças, mas também é modificado pelas mudanças inclusive nas questões da violência, visto que parte dessa sociedade.

\section{REFERÊNCIAS}

ALVES, José Augusto Lindgren. Os Bálcãs novamente esquecidos. Revista Brasileira de Política Internacional, v. 47, n. 1, p. 55-83, jan.-jun. 2004.

BOURDIEU, Pierre. A economia das trocas simbólicas. São Paulo: Perspectiva, 1998.

BOURDIEU, Pierre. O poder simbólico. Rio de Janeiro: Bertrand Brasil, 1998.

CAMUS, Jean-Yves; MONZAT, René. Les droites nationales et radicales en France. Lyon: Presses universitaires de Lyon, 1992.

CHARTIER, Roger. A construção estética da realidade - vagabundos e pícaros na Idade Moderna. Revista Tempo, v. 9, n. 17, p. 33-51, jul.-jan. 2004.

CHARTIER, Roger. A história cultural entre práticas e representações. Rio de Janeiro: Bertrand Brasil, 1990.

CURI, Martin. Tor zur Welt: Fußball als Realitätsmodell - gol para o mundo: futebol como modelo de realidade. Esporte e Sociedade, n. 1, p. 1-7, fev. 2006.

ELIAS, Norbert; DUNNING, Erick. A busca da excitação. Lisboa: DIFEL, 1992. FOER, Franklin. Como o futebol explica o mundo: um olhar inesperado sobre a globalização. Rio de Janeiro: Jorge Zahar, 2005.

FOUCAULT, Michel. Vigiar e punir. Petrópolis: Vozes, 2004. 
GLENNY, Misha. McMáfia: crime sem fronteiras. São Paulo: Companhia das Letras, 2008.

MARIVOET, Salomé. Violência nos espetáculos de futebol. Revista Sociologia Problemas e Práticas, n. 12, p. 137-153, 1992.

MURAD, Maurício. A violência e o futebol: dos estudos clássicos aos dias de hoje. Rio de Janeiro: FGV, 2007, p. 18-20.

MURPHY, Patrick; WILLIAMS John; DUNNING, Eric. O futebol no banco dos réus: violência dos espectadores num desporto em mudança. Oeiras, Portugal: Celta Editora, 1994.

PIMENTA, Carlos Alberto Máximo. Torcidas organizadas de futebol identidade e identificações, dimensões cotidianas. In: ALABARCES, Pablo (Org.). Futbologías: fútbol, identidad y violencia en América Latina. Buenos Aires: CLACSO, 2003, p. 39-55.

SEVCENKO, Nicolau. Futebol, metrópoles e desatinos. Revista USP, n. 22, p. 30-37, 1994.

STEWART, Christopher. Hunting the tiger: the fast life and violent death of the Balkans' most dangerous man. New York: St. Martin's Press, 2008.

THE GUARDIAN. Obtuaries. Londres: 19 de janeiro de 2000.

WOODWARD, Kathryn. Identidade e diferença: uma introdução conceitual. In: SILVA, Tomaz Tadeu (Org.). Identidade e diferença: a perspectiva dos estudos culturais. Petrópolis: Vozes, 2000, p. 7-72.

REFERÊNCIAS ELETRÔNICAS

LE MONDE. Guerre de Bosnie: Ron Haviviv recontre son image emblématique. Paris: 6 de abril de 2002. Obtuaries. Disponível em: https://goo.gl/SwjJS2. Acesso em: 25 nov. 2017. 